\title{
Sex identification of ancient DNA samples using a microfluidic device
}

Kirsty J Shaw, Keri A. Brown, Terence A. Brown and Stephen J. Haswell

\section{Summary}

Ancient DNA is the name given to the degraded, fragmented and chemically damaged biomolecules that can be recovered from archaeological remains of plants, animals and humans. Where ancient human DNA has survived at archaeological sites it can give valuable information and is especially useful for its potential to identify kinship, population affinities, pathogens and biological sex. Here, we describe the operation of a microfluidic device for the sex identification of ancient DNA samples using an efficient sample handling process. DNA is extracted from powered bone samples and abasic sites labelled with biotin. Streptavidin-coated superparamagnetic particles are used to isolate the labelled DNA prior to amplification of the Amelogenin sex marker.

\section{Keywords}

Ancient DNA, DNA extraction, Lab-on-a-Chip, Polymerase chain reaction, Sex identification

\section{Introduction}

Ancient human DNA analysis is not routinely applied in archaeology because of three major problems: contamination with modern human DNA, costs associated with specialist facilities and a limited range of 
suitable analytical methods and complex bioinformatic analysis (1). The use of a Lab-on-a-Chip (LOC) system aims to overcome some of these limitations by combining DNA extraction and amplification techniques on a single device to which powdered bone samples can be added directly and then the system sealed to minimise contamination.

Due to its nature, ancient DNA is often damaged and can contain many abasic sites (2). These abasic sites can be exploited to selectively enrich populations of damaged DNA by reacting them with an aldehydereactive probe (ARP) which is labelled with biotin. ARP undergoes a Schiff's base reaction resulting in biotin labelling of any abasic sites present within the DNA structure (3). By using streptavidin-coated paramagnetic beads the labelled DNA can be isolated and purified to ensure they are free of contaminants prior to amplification. In order to enable sex identification, the PCR target was the Amelogenin gene, which is present on the $X$ and $Y$ chromosomes. A 6 bp deletion within the amplified region of the $\mathrm{X}$ version of the gene means that the sizes of the PCR products indicate which chromosomes are present, the $\mathrm{X}$ product being $104 \mathrm{bp}$ and the $\mathrm{Y}$ version $110 \mathrm{bp}$ (4).

Integration of purification and amplification techniques is not without its challenges; in particular those issues raised by confinement of the solid-phase matrix, chemical compatibility and surface properties of the device required for the different stages (5). The methodology presented here uses a combination of magnetic and electrokinetic pumping mechanisms to achieve movement of reagents. An external magnet is used to manipulate the position of the paramagnetic beads 
within the device, while electro-osmotic flow (EOF) is used to drive the bulk flow of solutions. In EOF, An electrical double layer is generated at the glass surface due to an electrostatic attraction of cations to the deprotonated silanol groups. The more diffuse mobile layer is pulled towards the cathode, in the presence of an applied electric field, dragging with it the bulk solution. In the absence of pressure difference across the length of the microfluidic channel, a flat flow profile is produced which means that all molecules exhibit the same velocity, except for those very close to the internal surface wall (6).

Here, we detail a method for efficient processing of powdered bone samples within a microfluidic system for DNA extraction and amplification, enabling sex identification in an environment which minimises the potential of contamination with modern DNA.

\section{Materials}

Prepare all solutions using ultrapure water (prepared by purifying deionised water to attain a sensitivity of $18 \mathrm{M} \Omega \mathrm{cm}$ at $25^{\circ} \mathrm{C}$ ). Diligently follow all waste disposal regulations when disposing waste materials.

\subsection{Preparation of Microfluidic Device}

1. Microfluidic device prepared using standard photolithography and wet etching techniques to produce the design shown in Figure 1. 
2. Silanisation solution: $150 \mathrm{mM}$ trichloro $(1 \mathrm{H}, 1 \mathrm{H}, 2 \mathrm{H}, 2 \mathrm{H}$ -

perfluorooctyl)silane (Sigma-Aldrich, UK) in 2,2,4-trimethylpentane (Fisher Scientific, UK) (see Note 1).

\subsection{DNA Extraction Components}

1. DNA extraction buffer: $0.5 \mathrm{M}$ ethylenediaminetetraacetic acid (EDTA) $\mathrm{pH}$ 8.0, $0.5 \%$ sodium dodecyl sulphate (SDS) and $100 \mu \mathrm{g}$ proteinase $\mathrm{K}$ in water (Sigma-Aldrich, UK) (see Note 2).

2. Solid-phase matrix: $1 \mu \mathrm{m}$ streptavidin-coated superparamagnetic polystyrene particles (Sigma-Aldrich, UK).

\subsection{DNA amplification components}

1. GoTaq ${ }^{\circledR}$ Hot Start DNA polymerase: $0.1 \mathrm{U} \mathrm{\mu L}^{-1}$ with $1 \times$ Colourless GoTaq ${ }^{\circledR}$ Flexi Buffer and $2 \mathrm{mM} \mathrm{MgCl} 2$ (Promega, UK).

2. Deoxynucleotide triphosphate mix: $200 \mu \mathrm{M}$ each (Bioline, UK).

3. Surface passivation mix: $0.2 \mu \mathrm{g} \mu \mathrm{L}^{-1}$ bovine serum albumin, $0.01 \%$ (w/v) poly(vinylpyrrolidine) and 0.1\% (v/v) Tween-20 (Sigma-Aldrich, UK).

4. Primer sequences for amplification of the Amelogenin locus: $0.5 \mu \mathrm{M}$ forward primer, 5'-FAM-CCC TGG GCT CTG TAA AGA A-3', and $0.5 \mu \mathrm{M}$ reverse primer, 5'-ATC AGA GCT TAA ACT GGG AAG CTG-3' (Eurofins MWG Operon, Germany) (see Note 3).

\subsection{Capillary Gel Electrophoresis Components}


1. Denaturing solution: $12 \mu \mathrm{L} \mathrm{Hi-Di \textrm {TM }}$ Formamide and $0.5 \mu \mathrm{L}$ GeneScan ${ }^{\mathrm{TM}}$ 500 LIZ ${ }^{\circledR}$ Size Standard per sample (Applied Biosystems, UK).

\section{Methods}

Carry out preparation of bone samples in laminar flow cabinet in an ultraclean room dedicated for ancient human DNA work. An overview of the design and operation of the microfluidic device is provided (Figure 1).

\subsection{Preparation of Microfluidic Device}

1. Silanise the PCR chamber ( $D$ in Figure 1 ) in order to minimise DNA polymerase adsorption by adding the silanisation solution to the chamber and incubating for 10 minutes at room temperature (see Note 4).

2. Wash with 2,2,4-trimethylpentane.

3. Wash with acetone.

4. Wash with distilled water and then place in a $100{ }^{\circ} \mathrm{C}$ oven to dry.

\subsection{Preparation of Bone Samples}

1. UV irradiate the outer surface of the bone to minimise contamination.

2. Use a dental pick to remove powdered bone from the spongy matrix within a broken end of the bone (see Note 5).

3. Add to the DNA extraction chamber ( $B$ in Figure 1 ) on microfluidic device and incubate with DNA extraction buffer for 24 hours. 


\subsection{DNA Extraction}

1 Add $5 \mathrm{mM}$ of biotinylated aldehyde reactive probe (ARP) [Invitrogen, UK] to the DNA extraction chamber and incubate for 1 hour at room temperature.

2 Add $5 \mu \mathrm{L}$ streptavidin-coated superparamagnetic polystyrene particles and allow to incubate for an hour at room temperature.

3 Immobilise the magnetic particles in the DNA extraction chamber by placing a NdFeB permanent magnet (Magnet Sales, UK) underneath the extraction chamber (see Note 6).

4 Wash the particles using PCR-grade (DNase/RNase free) water to remove potential contaminants. Place platinum wire electrodes within inlets $A, C$ and E (see Figure 1) and connect to an external Paragon 3B Power Supply Unit (Kingfield Electronics, UK). Apply a voltage of $100 \mathrm{~V} \mathrm{~cm}^{-1}$ between both electrodes A to C and A to E to facilitate EOF (see Notes $\mathbf{7}$ and 8).

5 Transfer the washed magnetic particles into the PCR chamber by manual movement of the NdFeB permanent magnet in the direction shown in Figure le (see Note 9).

\subsection{DNA Amplification}

1 Add PCR reagent solution containing GoTaq ${ }^{\circledR}$ Hot Start DNA polymerase, deoxynucleotide triphosphate mix, surface passivation mix and primer sequences for amplification of the Amelogenin locus solution.

2 Carry out thermal cycling using the following heat programme: 4 minutes at $94{ }^{\circ} \mathrm{C}$; followed by 44 cycles of 1 minute at $55{ }^{\circ} \mathrm{C}, 1$ 
minute at $72{ }^{\circ} \mathrm{C}$ and 1 minute at $94{ }^{\circ} \mathrm{C}$; followed by 1 min at $55{ }^{\circ} \mathrm{C}$ and 10 minutes at $72{ }^{\circ} \mathrm{C}$ (see Notes 10 and 11).

\subsection{Capillary Gel Electrophoresis}

1. Use a pipette to remove the PCR product from the microfluidic device and store in a $200 \mu \mathrm{L}$ sterile tube until required.

2. Add $1 \mu \mathrm{L}$ of PCR product to $12.5 \mu \mathrm{L}$ of denaturing solution and denature for 5 minutes at $95^{\circ} \mathrm{C}$ before snap-cooling on ice.

3. Load onto 3500 Genetic Analyzer (Applied Biosystems, UK) following manufacturer protocols.

4. Following electrophoresis run, analyse data to identify the sex of the remains, where the $\mathrm{X}$ product is $104 \mathrm{bp}$ and the $\mathrm{Y}$ product is $110 \mathrm{bp}$ indicating male $(X Y)$ or female $(X X)$.

\section{$4 \quad$ Notes}

1. The silanisation solution has a limited shelf-life and should be prepared immediately prior to use. Avoid exposure of the reagents to water by storing the stock reagents with molecular sieve and drying all glassware prior to use in an oven.

2. SDS can precipitate and so the solution may need warming prior to use.

3. The forward primer has been labelled with FAM to facilitate fluorescence detection during capillary gel electrophoresis but different labels could be used. 
4. As well as the glassware to be used in the preparation of silanisation solution, it is also advisable to wash the microfluidic device with $100 \%$ ethanol and then place in a $100{ }^{\circ} \mathrm{C}$ oven to ensure that it is completely dry prior to use. Remove from the oven and place in a desiccator to maintain a moisture-free environment prior to addition of silanisation solution.

5. Using a toothpick to remove bone powder rather than a drill prevents heating caused by friction which can potentially damage the DNA.

6. An ideal sized NdFeB permanent magnet is $5 \times 3 \times 3 \mathrm{~mm}$.

7. To ensure optimal functioning of the platinum electrodes, clean in between runs using very fine sand paper and then washing in ethanol.

8. While carrying out electrokinetic movement, cool the microfluidic device to $4{ }^{\circ} \mathrm{C}$, using the thermoelectric Peltier element, in order to reduce Joule heating and minimise sample evaporation.

9. Movement of the external magnet needs to be performed in a controlled manner and monitored to ensure that the magnetic beads are transferred into the PCR chamber.

10. When carrying out DNA amplification on a microfluidic system using a Peltier thermoelectric Peltier element ensure that the desired temperature settings are those which occur inside the DNA amplification chamber on the device, which may require setting of higher temperatures on the Peltier element to achieve the desired temperature within the device. 
11. Cover all inlets with a drop of mineral oil to prevent evaporation during the thermal cycling process and minimise contamination.

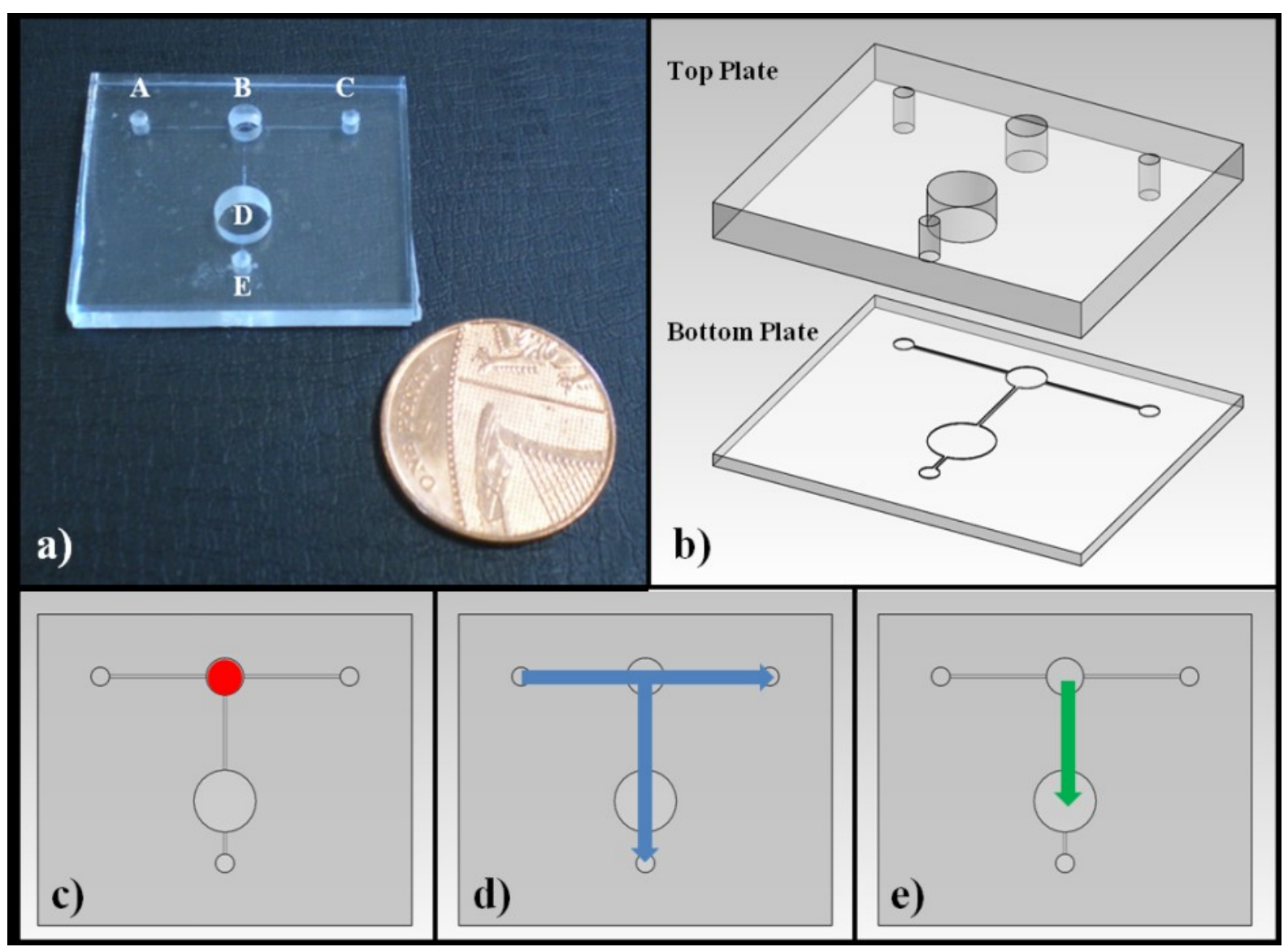

Figure 1: a) Photograph showing the microfluidic device used for integrated DNA extraction and amplification experiments, where $A, C$ and $\mathrm{E}$ are the $1 \mathrm{~mm}$ inlet/outlet holes for reagent/electrode addition; $\mathrm{B}$ is the DNA extraction chamber and $D$ is the PCR chamber; b) diagram showing the composition of the two layer microfluidic device where the bottom plate was etched to a depth of $100 \mu \mathrm{m}$; Schematic overviewing the operation of the microfluidic device for DNA extraction and amplification where c) is the location for introduction of the sample and solid-phase (DNA extraction chamber); d) shows the flow path of the wash solutions (A 
to $\mathrm{C}$ and $\mathrm{E}$ ) and e) demonstrates the transfer of the magnetic particles into the PCR chamber for DNA amplification. Reproduced from Shaw et al., 2013, with kind permission from Elsevier (7).

\section{References}

(1) Brown TA, Brown KA (2011) Biomolecular Archaeology: An Introduction. Wiley-Blackwell

(2) Pääbo S, Poinar H, Serre D, Jaenicke-Després V, Hebler J, Rohland N, Kuch M, Krause J, Vigilant L, Hofreiter M (2004) Genetic analyses from ancient DNA. pp. 645-679

(3) Fundador E, Rusling J (2007) Detection of labeled abasic sites in damaged DNA by capillary electrophoresis with laser-induced fluorescence. Analytical and Bioanalytical Chemistry 387: 1883-1890

(4) Sullivan KM, Mannucci A, Kimpton CP, Gill P (1993) A rapid and quantitative DNA sex test: Fluorescence-based PCR analysis of X-Y homologous gene amelogenin. BioTechniques 15: 636-641

(5) Ferrance JP, Wu QR, Giordano B, Hernandez C, Kwok Y, Snow K, Thibodeau S, Landers JP (2003) Developments toward a complete micro-total analysis system for Duchenne muscular dystrophy diagnosis. Analytica Chimica Acta 500: 223-236

(6) Taylor JA, Yeung ES (1993) Imaging of hydrodynamic and electrokinetic flow profiles in capillaries. Analytical Chemistry 65: 2928-2932 
(7) Parton J, Abu-Mandil Hassan N, Brown TA, Haswell SJ, Brown KA, Shaw KJ (2013) Sex identification of ancient DNA samples using a microfluidic device. Journal of Archaeological Science 40: 705-711 